\begin{tabular}{lll}
\hline Bentham OPEN & The Open Nursing Journal & $\begin{array}{l}\text { The } \\
\text { Open Nursing } \\
\text { lournal }\end{array}$ \\
\hline CrossMark & Content list available at: www.benthamopen.com/TONURSJ/ & DOI: $10.2174 / 187443460160101078$ \\
\hline
\end{tabular}

\title{
Mini Review of Integrated Care and Implications for Advanced Practice Nurse Role
}

\author{
Diana McIntosh", Laura F. Startsman and Suzanne Perraud \\ University of Cincinnati, College of Nursing, PO Box 210038, Cincinnati, Ohio 45219, USA
}

Received: March 20, 2015

Revised: June 2, 2015

Accepted: June 15, 2015

\begin{abstract}
:
Literature related to primary care and behavioral health integration initiatives is becoming abundant. The United States' 2010 Patient Protection and Affordable Care Act included provisions encouraging increased collaboration of care for individuals with behavioral and physical health service needs in the public sector. There is relatively little known of Advanced Practice Registered Nurses' (APRNs) roles with integrating primary and behavioral healthcare. The goal of this review article is to: (a) define integration of physical and behavioral healthcare and potential models; (b) answer the question as to what are effective evidence based models/strategies for integrating behavioral health and primary care; (c) explore the future role and innovations of APRNs in the integration of physical and behavioral healthcare.
\end{abstract}

\section{Results:}

The evidence- based literature is limited to three systematic reviews and six randomized controlled trials. It was difficult to generalize the data and the effective integration strategies varied from such interventions as care management to use of sertraline to depression management and to access. There were, though, implications for the integrated care advanced practice nurse to have roles inclusive of competencies, leadership, engagement, collaboration and advocacy.

Keywords: Advanced nurse practitioner, collaborative care, co-located care, evidence-based interventions, integrated care, mental health, primary care, randomized control trials.

\section{INTRODUCTION}

The older sister of a 60-year-old male patient, Tom, who was diagnosed many years with bipolar illness, accompanied him to a mental health appointment for assessment and refills. "Tom has stopped his lithium and I am worried about him." The Advanced Practice Nurse (APRN) noted that Tom's color was pale and pasty. He was pacing in the office. Tom stated, "The evil spirits are tearing my chest apart." The sister piped in, "That is because he stopped his lithium." The APRN continued her assessment, discovering Tom had gone to the emergency room (ER) two days prior for the "evil spirits". The ER sent him home with instructions to take his lithium. The APRN also discovered the sister had open heart surgery 2 years ago. The APRN arranged for Tom to go to the ER and communicated with the nurse that there was possibly a cardiac reason for the "evil spirits". Tom had quadruple by-pass surgery that afternoon and began his lithium again a few days later.

Tom's story is not unique. Studies have demonstrated correlations between physical and mental health related issues. A World Health Organization report listed seven reasons for integrating mental health into primary care: burden of mental illness is large; mental and physical health problems are interwoven: the treatment gap for mental disorders is great; primary care settings improve access for mental health services; integration may reduce stigma and discrimination; integrated care is more cost-effective; and most people with mental disorders treated in collaborative

\footnotetext{
* Address correspondence to this author at the University of Cincinnati, College of Nursing, PO Box 210038, Cincinnati, Ohio 45219, USA; Tel: 513-558-5207; Fax: 513-558-2142; Email: Diana.mcintosh@uc.edu
} 
primary care have improved outcomes [1]. The Patient Protection and Affordable Care Act is a United States (US) healthcare reform law enacted in March 2010 that includes provisions that will encourage increased collaboration of care for individuals with behavioral and physical health service needs in the public sector. The Affordable Care Act (ACA) is used to refer to the final, amended version of the law [2].

Literature related to primary care and behavioral health integration initiatives is becoming abundant. There is a growing wealth of reports on practical field experience as well as research studies [3]. The U.S. Substance Abuse and Mental Health Services Administration incorporated in their 2015-2018 strategic plan, Leading Change 2, an initiative addressing health care and health systems integration. Specifically, the plan includes a goal that aims to foster integration between behavioral health and health care, social support, and prevention systems [4]. All of these collective resources support integrated care as one strategy in meeting the triple aim of controlling healthcare costs, improving clinical outcomes, and improving the care experience for patients/consumers.

Although much has been published in the past 5 years about the integration of primary and behavioral healthcare, there are few randomized trials. APRNs may be exposed to general information about integrated healthcare, but might not be aware of the evidence based research on effective models or strategies in implementing integration. Also, relatively little is known about the role of APRNs with integrating primary and behavioral healthcare.

The goal of this review article is to: (a) define integration of physical and behavioral healthcare and potential models; (b) compare and contrast the literature, including effective evidence based models/strategies for integrating behavioral health and primary care; and (c) explore the future role and innovations of APRNs in the integration of physical and behavioral healthcare.

\section{METHOD}

To identify studies related to integration of behavioral health and primary care, including innovative evidence-based strategies, a literature search was conducted using electronic databases and manual searches. The sources were PubMed, CINAHL and the reference lists of identified studies. Searches were first conducted using general phrases of "integration, behavioral health and primary care". Articles published prior to 2008 were excluded in order to maintain the currency of the data. The sources were restricted to English-language peer-reviewed articles. CINAHL yielded 297 total sources that met the initial criteria; PubMed listed another 415 . The review examined both research and nonresearch articles to include every perspective in the integrative care movement.

The research studies were confined to the US in the interest of capturing the influence of the ACA [2] on integrated care. Initially titles of papers and abstracts were examined. If relevant, full papers were read to select the articles for this review. To be included in this paper, articles had to be published within the last 5 years. Evidence- based research articles had to include an experimental or quasi-experimental implementation strategy intended to integrate primary care and behavioral healthcare. There were only three systematic reviews and six randomized controlled studies between 2009 and 2014 that explored integration of primary care and behavioral healthcare and were included in the review.

\section{RESULTS}

\section{What is Integrated Healthcare?}

APRNs are keenly aware of trends related to integrating primary and behavioral healthcare. Many are familiar with the ACA and other national initiatives, including establishing medical homes and Accountable Care Organizations (ACO's), and terms like primary care and coordination of care (see Table $\mathbf{1}$ for definition of terms). Traditionally nursing has emphasized an integrated or "holistic" approach to assessing and delivering care to patients and their families. Recently, APRNs have begun to explore their roles in developing, implementing and evaluating models of integrated behavioral health care into primary care settings and primary care into behavioral health settings [5].

Table 1. 2010 Affordable Care Act partial definition of terms.

\begin{tabular}{|l|l|}
\hline \multicolumn{1}{|c|}{ Terms } & \multicolumn{1}{c|}{ Definitions } \\
\hline $\begin{array}{l}\text { Accountable Care Organizations } \\
\text { (ACO)s }\end{array}$ & $\begin{array}{l}\bullet \text { Health care provider groups who give coordinated care, chronic disease management, and } \\
\text { improve patient's quality of care. } \\
\bullet \text { Payment of services connected to quality goals and outcomes resulting in cost savings. }\end{array}$ \\
\hline
\end{tabular}




\begin{tabular}{|l|l|}
\hline \multicolumn{1}{|c|}{ Terms } & \multicolumn{1}{c|}{ Definitions } \\
\hline Medical Home contd.... & $\begin{array}{l}\text { - Delivery of primary care inclusive of: } \\
\text { 1. Patients having close contact with clinicians (physician, nurse practitioner, or } \\
\text { physician assistant) for continuing care } \\
\text { 2. Clinicians leading referrals to specialists } \\
\text { 3. Electronic health records } \\
\text { 4. Participation of patient and families } \\
\text { - Demonstrates philosophy of integration }\end{array}$ \\
\hline CareCoordination & $\begin{array}{l}\text { Organization of treatment across several health care providers. } \\
\text { - Medical homes and ACOs are common ways to coordinate care. }\end{array}$ \\
\hline Primary Care & $\begin{array}{l}\text { Health services covering a range of prevention, wellness, and treatment for common } \\
\text { illnesses. } \\
\text { - Providers include doctors, nurses, nurse practitioners, and physician assistants who } \\
\text { maintain long-term relationships with patients and coordinate care with specialists. }\end{array}$ \\
\hline
\end{tabular}

Adapted from The Kaiser Foundation Affordable Care Act Summary; 2012 [cited 23 November 2014] Available from: http://kff.org/health-reform/fact-sheet/summary-of-the-affordable-care-act/ and https:/www.healthcare.gov/glossary/\#Nanchor [6].

There is, however, variability in nursing and in the healthcare field regarding standardized definitions and vocabulary of integrated healthcare. Primary and behavioral health integration is referred to as "integrated care," "collaborative care", "co-located care," "shared care," "primary care behavioral health," “ multidisciplinary care", "integrative physical and mental health services" "integrated primary care", "care coordination", "holistic assessment", or "bidirectional integration" just to name a few [1, 3 - 10].Although all of these terms incorporate ideas that are comparable, they represent different provider perspectives, areas of the country and discipline traditions.

For instance, the Lewin group [10] in their 2012 report to the Center for Medicare and Medicaid state, "Integrated care is comprehensive, personalized, and consumer-centered. Comprehensive care encompasses mental, behavioral and physical health conditions and considers the influence of multiple conditions, social factors, social functioning, and consumer preferences to personalize assessments, treatments, and goals of care" [p. 1]. The Hogg Foundation [11] in their resource guide states, “...in essence integrated health care is the systematic coordination of physical and behavioral health care. The idea is that physical and behavioral health problems often occur at the same time. Integrating services to treat both will yield the best results and be the most acceptable and effective approach for those being served" [p. 7].

A universal definition is needed that is based on purpose. Delivery models may vary, but all share a common goal of integrating care to better serve the whole person. For the purpose of this article, integrated healthcare will be defined as described in the Lexicon report [12], published by the Agency for Healthcare Research and Quality, "the care that results from a practice team of primary care and behavioral health clinicians, working together with patients and families, using a systematic and cost-effective approach to provide patient-centered care for a defined population" [p. $15]$.

\section{What are Models of Integrated Care?}

In 2010, the Milbank Memorial Fund commissioned Collins et al. [13] to compile a report for policymakers with a primer on integrated care. It included various models that have led to a continuum of integration and collaboration. They discovered that innovative programs were first developed in the Veterans Health Administration, federally qualified health centers (such as the Cherokee Health Systems in East Tennessee) and health maintenance organizations (HMOs), such as Kaiser Permanente. They noted four concepts common to all models of integrated care: the medical home, the health care team, stepped care, and the four-quadrant clinical integration that identified populations best served in primary care versus behavioral healthcare (see Table 2).

Table 2. Definitions of four concepts common to integrated care models.

\begin{tabular}{|l|l|}
\hline \multicolumn{1}{|c|}{ Concepts } & \multicolumn{1}{c|}{ Definitions } \\
\hline Medical Home & $\begin{array}{l}\text { Primary care delivery method that may be more affordable, improve quality and exemplifies the philosophy of integrated } \\
\text { care and coordination by primary caregivers or teams. }\end{array}$ \\
\hline Health Care Team & A team that replaces doctor -patient relationships and there are shared responsibilities for patient care among team members. \\
\hline
\end{tabular}




\begin{tabular}{|c|c|}
\hline Concepts & Definitions \\
\hline Stepped Care & $\begin{array}{l}\text { Effective care offered by health care providers that is least intensive and expensive. Except in acutely ill patients, health } \\
\text { care providers should offer care with effective service that is least intensive and expensive. If patients' functioning does not } \\
\text { improve through usual course of care, the intensity of services are customized according to patients' responses and may be } \\
\text { stepped down if appropriate. }\end{array}$ \\
\hline $\begin{array}{l}\text { Four Quadrant Clinical } \\
\text { Integration }\end{array}$ & $\begin{array}{l}\text { Model that identifies populations to be served in primary care versus specialty behavioral health } \\
\text { Primary Care Settings: } \\
\text { - Quadrant I: Low behavioral and physical health needs. } \\
\text { - Quadrant III: Low behavioral health/High physical health needs. } \\
\text { Primary Care and Specialty Mental Health Settings: } \\
\text { - Quadrant II: High behavioral health/Low physical health needs. } \\
\text { - Quadrant IV: High behavioral and physical health needs. }\end{array}$ \\
\hline
\end{tabular}

The Collins et al. [13] report cites eight models ranging from minimal collaboration to partial integration (colocated) to full integration. For instance, the first model improves collaboration between separate providers using coordinated efforts. The providers' practices are completely separate with different administrative structures and financing/reimburse-ment systems. Although there are a number of common strategies used in this practice model, there are no randomized controlled trials (RCTs) using this model and the anecdotal reports are mixed. Also, the practice provider cultural issues are enormous in this model [13]. Another model described was reverse co-location. Initially, integration was mainly considered from the perspective of integrating behavioral health care into primary care, but it is now known that the reverse approach is also possible. In this reverse co-location model, there is an emphasis on improving the physical health care for persons with severe and persistent mental illness. Studies on the effectiveness of this type of co-location are still in their infancy. The eighth model is a hybrid, collaborative system of care, either partly or fully integrated depending on degree of collaboration. A system of care is an integrated model with a collaborative system of services wrapped around the child and family and widely used in children's mental health [14] Evaluations of this model are varied, with some demonstrating effective outcomes and others not being so positive. It is not possible to draw any absolute conclusions [13].

Although not all models were detailed above, they all were cited in the report with examples, successes, and when available, evidence-based research. The summary of models may be useful for the broad concepts, but should not be used for exact replication of implementation [13].

\section{Integration of Primary Care and Behavioral Healthcare: Systematic Reviews}

Three systematic reviews related specifically to integrated care have been conducted in the last 5 years. Van der Feltz-Cornelis et al. [15] conducted a review and meta-analysis to establish the effectiveness of antidepressant medications with persons who have depression and diabetes. The review used data sources of PubMed, Psycinfo, Embase and Cochrane library with the resultant meta-analysis of 14 RCTs ( $n=1724$ patients). They evaluated treatment by psychotherapy, pharmacotherapy or collaborative care of depression in persons with Type 1 and Type 2 diabetes mellitus. The results showed treatment was effective for reducing depressive symptoms $(-0.512 ; 95 \% \mathrm{CI}-0.633$ to -0.390$)$. Also, the combined effect of all interventions on clinical impact was moderate $(-0.370 ; 95 \% \mathrm{CI}-0.4701$ to -0.271). The effect size was moderate for pharmacotherapy $(0.467 ; 95 \%$ CI -0.665 to $-0.270, n=281)$ and large for psychotherapy interventions combined with diabetes self-management $(0.581 ; 95 \%$ CI -0.70 to $-0.391, n=301)$. There was a large effect size obtained on a population scale with the stepped care intervention starting with psychotherapy or pharmacotherapy to a primary care population $(-0.292 ; 95 \%$ CI -0.429 to $0.155, n=1133)$. Although the number of RCTs was small, it did show some promise with collaborative care and illustrated the need for further research on the integrated treatment of depression in persons with diabetes.

Another systematic review completed by Butler et al. [16] assessed whether the level of integration of behavioral health in primary care settings affected clinical outcomes. After reviewing and categorizing 33 clinical trials articles from 1950-2007, there were 26 that met inclusion criteria and kept for review. All of the integrated models published after 2000 used care managers and focused on depression care, not on the entirety of health problems patients might be experiencing. Interestingly, most trials demonstrated positive effects, but results were not consistent. One evidencedbased program, IMPACT (Improving Mood - Providing Access to Collaborative Treatment), demonstrated improvements in symptom severity. Studies reveal IMPACT also improves physical and social functioning, patients' quality of life and reduces healthcare costs. The IMPACT Implementation Center has trained over 4,000 clinicians and supported implementation of this evidence-based program in more than 500 clinics [17]. There was no correlation 
between the outcomes and the extent of clinician integration or level of the integrated care intervention. Although the results of this review should be viewed as exploratory, it does raise some important issues including viewing integration from a holistic perspective without focusing on only one condition.

Woltmann et al. [18] conducted a meta-analysis of relevant published or in press RCTs through August 15, 2011 to assess the comparative effectiveness of collaborative chronic care models for mental health conditions in various treatment settings. Although this is not inclusively about integrated care, it did include about $20 \%$ of trials that were designed for populations with combined behavioral health and medical disorders. There were 78 articles reviewed, which represented 57 trials, the majority being depression $(\mathrm{N}=40)$, followed by bipolar $(\mathrm{N}=4)$; anxiety $(\mathrm{N}=3)$, and multiple other disorders $(\mathrm{N}=10)$. The meta-analysis revealed significant t effects (Cohen's d values, 0.20-0.33) across depression and care settings as well as from mental and physical quality of life and social role function. The conclusion was that collaborative chronic care model could improve outcomes, both mental and physical for persons with mental health conditions, particularly depression, across various treatment settings. This has implications for policy framework in integration.

All systematic reviews accentuated the fact that actual RCTs on integrated care, particularly if confined to the US, are rare. Van der Feltz-Cornelis et al. [14] did not confine their review to the US and found even with over 3000 initial hits; only 15 were randomly controlled studies. Fourteen met criteria for their meta-analysis and only four of these were from 2004-2009. Similarly, Butler et al. [16] spanned 57 years to find 33 clinical trial articles on integration of behavioral health in primary care settings. Woltmann's et al. [18] meta-analysis revealed only 12 articles that specifically addressed integrated care. All reviews were written by physicians or people with Ph.D.'s, and did not involve nurses. This highlights a gap in nursing research of RCTs related to integration of primary care and behavioral health.

Robinson and Strosahl [19] in their non-empirical article reflected lessons they learned in their 20 years of experience with integrating behavioral health services into primary care and raise the issue that condition- based integration efforts may not be effective. Nonetheless, researchers continue to examine interventions that are condition based, with depression and diabetes in particular. Consequently, this condition-based focus impacts the APRNs ability to practice using evidence- based treatment across their scope of practice. A review of six RCTs in integrated care completed in the US (2009-2014) is presented below (See Table 3 for specific information on purpose, design and outcomes). The RCTs fall into two main categories, the integration of behavioral healthcare into primary care and the integration of primary care into behavioral health.

Table 3. Evidence based interventions related to integrated care 2009-2014 by setting type.

\begin{tabular}{|c|c|c|c|c|}
\hline \multicolumn{5}{|c|}{ Behavioral Health into Primary Care } \\
\hline Author & Intervention & Design & Sample & Findings/Outcomes \\
\hline $\begin{array}{l}\text { Alexopoulos et } \\
\text { al. [20] }\end{array}$ & $\begin{array}{l}\text { PROSPECT: Care management } \\
\text { intervention } \\
15 \text { trained care managers offered } \\
\text { physician } \\
\text { recommendations \& } \text { algorithm-based } \\
\text { treatment compliance }\end{array}$ & RCT & 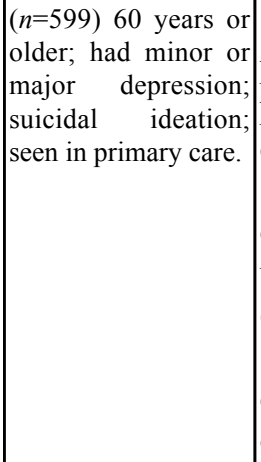 & $\begin{array}{l}\text { - Intervention group more likely to: be } \\
\text { prescribed antidepressants } \\
\text { psychotherapy; have } 2.2 \text { times greater } \\
\text { decline in suicide ideation than usual care. } \\
\text { - Intervention group patients with major } \\
\text { depression: more attained remission than } \\
\text { usual care \& sustained through } 24 \text { month } \\
(45.4 \% \text { vs } 31.5 \%) \text {. } \\
\text { - No difference in patients with minor } \\
\text { depression, both groups with favorable } \\
\text { outcomes. }\end{array}$ \\
\hline $\begin{array}{l}\text { Echeverry et al. } \\
\text { [21] }\end{array}$ & $\mid \begin{array}{ll}\text { Antidepressant use } & \text { in minority } \\
\text { population with } & \text { uncontrolled } \\
\text { diabetes to improve } & \mathrm{HgAlc} \text { and } \\
\text { QOL } & \end{array}$ & \begin{tabular}{|lr} 
RCT & double \\
bind & placebo \\
control &
\end{tabular} & $\mid \begin{array}{lr}n \quad=\quad 89 ; & 75 \\
\text { completed }) & \mathrm{HgA} 1 \mathrm{c} \\
\text { levels of }< & 8 \% \text { and } \\
\text { depression } & \end{array}$ & $\begin{array}{l}\text { - Sertraline group significantly greater } \\
\text { decrease in } \operatorname{HgA} 1 \mathrm{c} \text { and systolic blood } \\
\text { pressure levels }\left(\mathrm{P}=0.45\left[\mathrm{P}<10^{-6}\right]\right) \text { compared } \\
\text { with placebo. } \\
\text { - No significant difference in QOL }\end{array}$ \\
\hline
\end{tabular}




\begin{tabular}{|c|c|c|c|c|}
\hline \multicolumn{5}{|c|}{ Behavioral Health into Primary Care } \\
\hline Hay et al. [22] & $\begin{array}{l}\text { Collaborative depression care } \\
\text { program among low-income } \\
\text { Hispanics with diabetes. } \\
\text { (Multifaceted Diabetes and } \\
\text { Depression Program) }\end{array}$ & RCT & \begin{tabular}{|lr}
$(\mathrm{n}=387)$ & $(96.5 \%$ \\
Hispanic) & with \\
diabetes & and \\
clinically & significant \\
depression & \\
& \\
& \\
&
\end{tabular} & $\begin{array}{l}\text { - Intervention significantly greater health } \\
\text { improvement compared with controls over } \\
18 \text {-month evaluation period }(4.8 \% \text { P }< \\
0.001) \text { and corresponding significant } \\
\text { improvement in depression-free days } \\
(43.0 ; \mathrm{P}<0.001) \text {. } \\
\text { - Medical cost differences were not } \\
\text { statistically significant. }\end{array}$ \\
\hline $\begin{array}{l}\text { Szymanski } \\
\text { al. [23] }\end{array}$ & $\begin{array}{l}\text { Compare primary care services (PC) } \\
\text { only with receiving primary care } \\
\text { and mental health integration } \\
\text { interventions (PC-MHI) or specialty } \\
\text { mental health interventions (SMI) }\end{array}$ & $\begin{array}{l}\text { Retrospective } \\
\text { Chart Review }\end{array}$ & $\begin{array}{l}(n=36,263) \\
\text { Veterans in primary } \\
\text { care setting } \\
\\
\end{array}$ & $\begin{array}{l}\text { - Patients who received same-day PC-MHI } \\
\text { services were more likely to begin } \\
\text { treatment, be it psychotherapy (OR: } 8.16 \text {; } \\
95 \% \text { CI: } 6.54-10.17 \text { ) and/or antidepressant } \\
\text { medications (OR: } 2.33,95 \% \text { CI: } 2.10 \\
-2.58 \text { ) within } 12 \text { weeks than those who } \\
\text { received only PC services on screening } \\
\text { days. }\end{array}$ \\
\hline \multicolumn{5}{|c|}{ Primary Care into Behavioral Health } \\
\hline Author & Intervention & Design & Sample & Findings/Outcomes \\
\hline $\begin{array}{l}\text { Druss et al. } \\
{[24]}\end{array}$ & $\begin{array}{l}\text { Tested population-based medical } \\
\text { care management intervention (care } \\
\text { managers, health education and } \\
\text { support) designed to improve } \\
\text { primary medical care in community } \\
\text { mental health settings. }\end{array}$ & RCT & $\begin{array}{l}(n=427) \\
\text { Persons in a } \\
\text { community mental } \\
\text { health setting }\end{array}$ & $\begin{array}{l}\text { Intervention group receiving significantly higher } \\
\text { proportion of: } \\
\text { Recommended preventive services } \\
(58.7 \% \text { versus } 21.8 \%) \text {; } \\
\text { Evidence based services for } \\
\text { cardiometabolic conditions }(34.9 \% \text { versus } \\
27.7 \%) \text {; } \\
\text { - Primary care providers }(71.2 \% \text { versus } \\
51.9 \%) \\
\text { Improvement on the SF-36 (8.0\% versus } \\
1.1 \% \text { decline in usual care group). }\end{array}$ \\
\hline $\begin{array}{l}\text { McGuire et al. } \\
{[25]}\end{array}$ & $\begin{array}{l}\text { Clinic integrating } \\
\text { primary care and mental health } \\
\text { services }\end{array}$ & Quasi exper- & $\left|\begin{array}{lr}(n=130) & \text { Veterans } \\
\text { homeless } & \text { with } \\
\text { serious mental illness } & \\
\text { or substance abuse }\end{array}\right|$ & $\begin{array}{l}\text { - Integrated care group was more quickly } \\
\text { enrolled in primary care and had } \\
\text { significantly higher number of primary } \\
\text { care visits (on average } 2.3 \text { visits more) } \\
\text { than usual care group } \\
\text { - Individuals with more prevention } \\
\text { services and primary care visits had fewer } \\
\text { emergency department visits } \\
\text { - No difference in inpatient utilization or in } \\
\text { physical health status when measured over } \\
18 \text { months. }\end{array}$ \\
\hline
\end{tabular}

\section{Integration of Behavioral Healthcare into Primary Care}

Of the four RCT's in this group that addressed introducing behavioral healthcare in primary care settings, three were condition-based [20 - 22], two involved a care management intervention in special populations (older adults with depression and suicidal ideation and mostly Hispanics with depression and diabetes)[20, 22], one retrospectively examined the impact of co-occurring assessment in 36,263 patient records containing positive screens for depression at a Veterans Health Administration (VA) primary care setting on time to treatment [23] and the last examined the use of antidepressants in a depressed and diabetic minority population [21].

The care models also varied, with Alexopopulos et al. [20] using trained care managers who, in the PROSPECT intervention group, supported treatment compliance and offered recommendations to providers based on algorithms. Hay et al. [22] incorporated a unique sociocultural adapted collaborative care depression management intervention called the MDDP, which was designed to increase patient exposure to evidence-based psychotherapy and/or pharmacotherapy in two public safety net clinics with mostly Hispanic patients. A variety of outcomes were also sought, from treatment compliance [20] to HgA1C levels [21], to cost effectiveness [22] and time to treatment [23]. 
In the study by Alexopoulos et al. [20], patients who received the intervention were more likely to be prescribed antidepressants or psychotherapy than usual care, resulting in a 2.2 times greater decline in suicide ideation and a greater number of persons with major depression who attained and sustained remission. Similarly, Hay et al. [22], while not finding significant medical cost differences did find those patients receiving a collaborative care intervention had significant increase in depression-free days $(t=43.0 ; \mathrm{P}<0.001)$.

Echeverry et al. [21] found treating patients with diabetes who screened positive for depression with sertraline resulted in significantly greater decreases in $\mathrm{HgA} 1 \mathrm{c}$ and systolic blood pressure levels $\left(\mathrm{P}=0.45 \mathrm{P}<10^{-6}\right)$. Szymanski et al . [23] found those patients receiving primary care and mental health integration interventions (PC-MHI) or specialty mental health interventions (SMI) on the day of screening were more likely to begin treatment, such as psychotherapy (OR: 8.16; 95\% CI: 6.54-10.17) or antidepressants (OR: 2.33; 95\% CI: 2.10-2.58) within 12 weeks than those who received only primary care screening.

\section{Integration of Primary Care into Behavioral Healthcare}

There were two RCT's in the US (2009-2014) that examined integration of primary care into behavioral healthcare settings. Both were designed to improve medical care to patients with mental illness or substance abuse. Druss et al. [24] used care managers in their intervention group who communicated and advocated with health providers, facilitated health education and gave support $(n=427)$. The care managers assisted with overcoming barriers to accessing primary medical care. McGuire et al. [25] did a longitudinal outcome study using a quasi-experimental design to compare a 'usual VA care' group before the demonstration clinic opened (PRI) and a second group that had access to the collocated primary care services, the 'integrated care' group (POI). In the POI group, the homeless veterans were evaluated in a screening clinic and quickly referred to all needed services that were co-located within the same building. The goal was to have initial primary care appointments occur the same day that the homeless veteran came to the screening clinic. Written policies and standard operating procedures, case conferences, and weekly building operational meetings facilitated communication and coordination. Case managers immediately initiated short-term case management. Providers in the co-located primary care clinic consisted of a lead primary care physician and three nurse practitioners and all received consultation and training regarding engaging and treating the homeless population.

Both studies met their goals to increase access to primary care for patients. Druss et al. [24] found after 12 months the intervention group accessed significantly more preventive services than the usual group $(58.79 \%$ versus $21.89 \%)$ and had a higher percentage of evidence- based services for cardio metabolic conditions. The intervention group was more likely to have a primary care provider, thus providing some evidence that having a care management model embedded in a community mental health setting may be a way of improving primary care access for persons who have behavioral health issues.

McGuire et al. [25] found the POI group patients had less than a day lapse before their initial scheduled primary care visit, while PRI group veterans had almost a 2- month wait for their first visit. Access to prevention services after 1 year was significantly higher for the POI group. The use of the ER by the POI group was significantly lower than the use by the PRI group. There was no change in use of inpatient services. Although access was clearly improved, there was no group difference in perceived physical health status.

\section{DISCUSSION}

\section{Summary of Studies on Integrated Care Interventions}

In spite of the abundance of literature and interest in integrated care, there are only six RCT studies published from 2009-2014 (Table 3). There were RCT studies that showed integration of mental health services into primary care [20 23 ] and those that showed integration of primary care into behavioral healthcare [24, 25]. The empirical evidence is limited and its implementation has been slow, not offering much guidance on integration.

While the majority of studies targeted specific conditions in behavioral or primary care settings, there were some results that bear illumination. These studies were targeted to persons who had: 1) depression and were seen in a primary care or integrated care setting [20 - 23]; 2) significant depression and diabetes [21, 22]; 3) mental illness and cardiovascular risk factors [21]; and 4) mental illness or substance abuse and physical health need [25]. Alexopoulos [20] and Hay [22]'s studies had adequate sample sizes and demonstrated collaborative care management interventions were more likely to result in depression free days for primary care patients. Development of such interventions lies directly in the wheelhouse of the APRN. Similarly, Druss et al. [24] found that a care management model improved 
access to primary care for persons who have behavioral health issues. McGuire [25] found improved access of care through the use of co-located behavioral health and primary care providers. While Echeverry's [21] study did not address collaborative care management, it did recognize the importance of integrated care in improving patients' diabetes management (HgAlc and blood pressure levels). Szymanski et al. [23] found another element impacting integration of care was the timeliness of providing treatment. That is, those receiving same day mental health interventions in a primary care setting facilitated participation in depression treatment.

Similar to Butler's [16] findings, this review found most of the RCT studies were very specific and did not address the entirety of health or mental health problems patients might be experiencing. Furthermore, the definitions of integration and the models used were inconsistent. As a result, it is challenging to answer the question: what are effective evidence-based models/strategies for integrating behavioral health and primary care? That is, if you read one evidence-based intervention for integration, you have read one evidence-based intervention. Nonetheless, the findings from the RCT offer some interesting implications for the role of the APRN with integrated care, which are discussed more fully in the next sections.

\section{Psychiatric Mental Health Advanced Practice Nurses with Integrated Care}

The RCT results along with the ACA provide ample evidence to impel APRNs to further develop the integrated care role and lead the way with innovations to increase access, advance retention and improve quality of integrated care. The ACA calls for support of workforce development and training programs focused on primary care models such as medical homes, team management of chronic disease, and those that integrate physical and mental health services [2]. Nurses are already positioned as experts in integrated care. The SAMHSA-HRSA Center for Integrated Health Solutions (CIHS) recently commissioned a group to develop integrated care core competencies. Several nurse leaders were invited to be key informants within the group because of their known expertise and experience in integrated care [26].

In 2013, the American Psychiatric Nurses Association (APNA) [27] put forth a primary care statement that addressed why psychiatric nursing is part of the primary care workforce. APNA in 2014 added to their Scope and Standards of Psychiatric Nursing a section on integrated care [28]. Even more recently, the APNA put out a call of interest for a position paper on "what would integrated physical and mental health care look like" [29]? The International Society for Psychiatric Nurses (ISPN) in 2015 is expected to complete a white paper on integrated care [30]. To broaden the issue, one might ask what the role of the integrated care APRN would look like in the future. APRNs need to be innovative, use evidence-based practice and mutually define their future integrated care role.

\section{Integrated Care Role of APRNs, Certification and Reimbursement}

Studies [23, 25] have found using an integrated care model helped improve access to health care and subsequent participation in preventive health and treatment. However, there are instances documented in which primary care providers did not take advantage of co-located mental health providers or made few referrals to behavioral health services, except for when referring those clients with anxiety and depression [31,32]. An argument can be made that for effective integration to occur, the same APRN needs to address both medical and behavioral health needs of patients. This single APRN can facilitate screening, access and preventive services as well as offer treatment all at the same time. APRNs are keenly aware of their scope of practice and know when to do the treatment themselves and when to refer to another providers [26].

When the CIHS engaged the Annapolis Coalition on Behavioral Health Workforce [26] to lead and manage the competency development project for integrated care, there were initially discussions regarding two sets of competencies, one for integrating behavioral health into primary care and one for integrating primary care into behavioral healthcare. Quickly it was realized the same core competencies would be applicable for both. The Core Competency Categories include: interpersonal communication, collaboration and teamwork, screening and assessment, care planning and care coordination, intervention, cultural competence and adaptation, systems oriented practice, practice-based learning and quality improvement, and informatics [26]. As this workforce recognized the need for one set of core competencies, perhaps nursing can support the same notion and facilitate one certification in integrated care rather than dual certification. This could be a staged process with nurse practitioners initially receiving dual certification in primary care specialties of adult, pediatrics or women's health along with behavioral health. At the renewal time, both certifications could be combined into one integrated care certification that is confirmed by the documented experience of the practitioner. This not only recognizes the unique skill sets and expertise needed by both separate 
specialties, but also would ultimately give birth to a new specialty area of integrated mental health and primary care.

APRNs competent in primary and behavioral healthcare would be positioned to treat more than diabetes and depression, assuming reimbursement structures are altered to allow these types of care by one practitioner [21, 22]. Nurse educators need to take heed and train future APRNs to have both competency sets. Support for this concept can be seen in the development of post master's psychiatric mental health nurse practitioner certificate programs that promote basic tenets of integrated care and dual certification [33 - 35].

Given the infrastructure does not exist for what it proposed presently, at a minimum health care teams today could consist of one primary care and one mental health APRN who work together to problem solve and holistically treat persons.

\section{Role of Engagement}

The majority of RCT studies cited elements that promote or give access to both primary and behavioral health care. They include such strategies as care management, patient education, prevention, co-location, screening, culturally sensitive care, self-management, and increased health team communication [15, 16, 20 - 25]. However, access does not guarantee motivation to self-manage behavioral or physical health issues. When patients are actively engaged in treatment, they optimize benefits of their health care. They select providers they can relate to and who help them make informed treatment decisions, including reviewing risks, benefits and alternative treatments. They become proficient in self-management and following their treatment plan. In 2011, the U.S. National Institute for Mental Health (NIMH) held a meeting to address their interest in developing and testing engagement strategies to improve access and increase positive patient outcomes for people with mental illness [36].

The stigma of mental illness may make it difficult for some people to access and engage in treatment. Because of relationship and therapy skills, integrated care APRNs would have unique abilities to actively engage patients and when necessary their family or significant others. For example, an integrated care APRN could engage a patient who had several miscarriages and is anxious and depressed by employing brief cognitive behavioral therapy. An integrated care APRN could engage, diagnosis, and help treat asthma in a patient with schizophrenia who thinks his breathing issues were the result of demons possessing his body. The ultimate result would be to effectively and efficiently treat both physical and behavioral health care issues, regardless of setting.

Integrated care APRNs of the future could be positioned to facilitate and lead the process of engagement with patients, particularly those in primary care who need behavioral health treatment. The literature identifies several engagement strategies, among them: being proficient at culturally sensitive screening and treatment, fostering interventions that promote patient activation and shared decision making in treatment decisions, educating patients on their issues and treatment options, supporting patient self-management, problem solving barriers to treatment, and using health information technology [36]. Integrated care APRNs would have the skill set to implement these strategies and facilitate other caregivers to effectively engage patients in their own physical and behavioral health care.

\section{Role of Collaborator}

Care coordination or care management was recognized as a significant strategy for the integration of physical and behavioral healthcare $[20,24]$. The future integrated care APRNs will promote the ultimate care coordination by using their ability to work in teams, with other providers, patients and their families to achieve mutually determined goals. They can role model for other team members how to stay focused on the whole person and not solely on disease management. They will have excellent skills in interpersonal communication, collaboration and teamwork, and work effectively with others in care planning and care coordination. They can employ this collaborative role with providers from other disciplines as well as nurses from other specialty areas.

An example of this team model is exemplified in Reiss-Brennan's work with the Intermountain mental health integration program (MHI). Each of the three basic components of the program include teams that use: 1) a mental health assessment tool that activates team consultation workflow for assessment of physical and mental health issues; 2) team protocols including mental health specialists and nurse care managers with primary care staff; and 3) program evaluation to monitor patient outcomes, team effectiveness and the culture of healthcare delivery from the perspective of the patient and the care provider [37].

Integrated care APRNs can also be excellent collaborators with researchers. They have the practice and clinical expertise to identify integrated care problems or issues. Research teams need nurses proficient in research and those 
with practice experience. This review revealed no RCT studies conducted by nurses [15, 6, 20 - 25]. If in the future integrated care APRNs partner with nurse researchers, it would exponentially extend the knowledge base of evidence based integrated care, APRN integrated care role, innovations, patient experiences, and quality of care.

\section{Role of Advocacy}

Nurses have traditionally been known as advocates for patients and their families. This role needs to continue and the future integrated care APRN role could expand advocacy efforts. Nurses need to be integrally involved in promoting evidence-based practices for integrated care $[15,16,20-25]$ and be knowledgeable about existing integrated care models to help systems and patients choose their best matches $[3,7,10]$. Integrated care APRNs must deliver clear statements about their role and advocate why they are positioned to lead teams for quality integrated care. They can advocate for relevant policies, such as support for integrated physical and behavioral health, role standardization, certification competencies or accreditation elements indicative of integrated care. They need to continue to be involved in national efforts [26] to move forward the integrated care agenda, such as nationally defining quality indicators expected from integrated care and identifying effective models and practice innovations. As Geis and Delany [38] so eloquently stated, "nurses need to strengthen their voices in advocating for the services they provide and ones clients say they need.’'[p. 436]

\section{Summary of Innovative Role of Integrated Care APRN}

Integration is the hallmark of the future of healthcare. Likewise, APRNs can be the hallmark providers of integrated care. Integrated care APRNs are set apart from the rest of healthcare providers and can effectively influence healthcare by clearly defining their role to include leader, engager, collaborator, and advocate, as well as achieve certification identifying their unique competencies. This change is not without obstacles. The infrastructure is not yet available in many educational and clinical settings to promote an integrated APRN. There are fellowships that offer the opportunity to develop competencies in integrated care, but educational costs and benefits are not widely documented. Also, the threat that integrating care might present to the identities of psychiatric mental health nurse practitioners (PMHNP) is real. PMHNPs may be concerned that if the specialty gets embedded in an integrated model, the core of their specialty may be lost. A future discussion of these challenges is warranted.

\section{CONCLUSION}

This review article defined integration of physical and behavioral healthcare and potential models, determined that effective evidence-based strategies for integrating behavioral health and primary care are challenging to generalize and explored the future role of APRNs in the integration of physical and behavioral healthcare. There are implications for the integrated care APRN to address obstacles and develop roles inclusive of integrated care competencies, leadership, engagement, collaboration and advocacy. APRNs are well positioned to address the challenges of integrating care and serve people with mental illness. They approach patients holistically; have excellent assessment and diagnostic skills, leadership skills, practice with evidence-based strategies and experience in teamwork and collaboration. Lastly, APRNs have a history of overcoming obstacles, such as those related to obtaining licensure and prescriptive authority. This involvement will serve them well in meeting the challenges of integrating care.

\section{CONFLICT OF INTEREST}

The authors confirm that this article content has no conflict of interest.

\section{ACKNOWLEDGEMENTS}

Declared none.

\section{REFERENCES}

[1] Funk M, Ivbijaro G. Integrating mental health into primary care-A global perspective [Internet]. $1^{\text {st }}$ ed. Geneva, Switzerland: World Health Organization and London, UK: World Organization of Family Doctors 2008 [cited 23 November 2014]; Available from: http://www.who.int/mental_health/policy/services/3_MHintoPHC_Infosheet.pdf?ua=1

[2] The Kaiser Foundation Affordable Care Act Summary [Internet] 2013 Apr 24; [cited 23 November 2014]; Available from: http://kff.org/health-reform/fact-sheet/summary-of-the-affordable-care-act/

[3] Avery M. Five key ingredients in the integrated care recipe. Nat Counc Mag 2014;(1): 49. [cited 23 November 2014]; Available from: https: $\mathrm{http}: / /$ www.thenationalcouncil.org/?api\&do=attachment\&name=many-faces-integration\&index $=0 \&$ type=magazine-issues\&inline \#page $=49$ 
[4] Substance Abuse and Mental Health Services Administration. Leading change 20: Advancing the behavioral health of the nation $2015-2018$. Rockville, MD: HHS 2014; pp. 1-40.

[5] Shea JM. Perspectives on integrated behavioral health care. Arch Psychiatr Nurs 2013; 27(6): 263 [http://dx.doi.org/10.1016/j.apnu.2013.10.006] [PMID: 24238004]

[6] U.S Centers for Medicare \& Medicaid Services. Healthcare.gov glossary of terms. [Internet]. Baltimore, MD: CMS, 2015; Available from: https://www.healthcare.gov/glossary/\#Nanchor

[7] A standard framework for levels of integrated healthcare. SAMHSA-HRSA 2013; pp. 1-13.

[8] Weiss SJ, Haber J, Horowitz JA, Stuart GW, Wolfe B. The inextricable nature of mental and physical health: implications for integrative care. J Am Psychiatr Nurses Assoc 2009; 15(6): 371-82 [http://dx.doi.org/10.1177/1078390309352513] [PMID: 21659251]

[9] Mauer BJ, Druss BG. Mind and body reunited: improving care at the behavioral and primary healthcare interface. J Behav Health Serv Res 2010; 37(4): 529-42. [http://dx.doi.org/10.1007/s11414-009-9176-0] [PMID: 19340586]

[10] Approaches to integrating physical health services into behavioral health organizations. Centers for Medicare and Medicaid 2012 ; pp. 1-31.

[11] Hogg Foundation: Integrated health care [Internet] 2014 [cited 23 November 2014]; Available from: http://www.hogg.utexas. edu/initiatives/integrated_health_care.html

[12] Peek CJ. Lexicon for behavioral health and primary care integration: Concepts and definitions developed by expert consensus. Rockville, MD: Agency for Healthcare Research and Quality 2013; pp. 1-57.

[13] Collins C, Levis Hewson D, Munger R, Wade T. Evolving models of behavioral health integration in primary care. $1^{\text {st ed }}$. New York, NY: Milbank Memorial Fund 2012. Internet [cited 23 November 2014]

[14] Strohl B, Blau G. Systems of Care for Children's Mental Health Series Brookes Publishing Co [Internet] 2012 [cited 23 November 2014$]$; Available from: http://www.brook espublishing.com/resource-center/book-series/systems-of-care-for-childrens-mental-health-series/

[15] van der Feltz-Cornelis CM, Nuyen J, Stoop C, et al. Effect of interventions for major depressive disorder and significant depressive symptoms in patients with diabetes mellitus: a systematic review and meta-analysis. Gen Hosp Psychiatry 2010; 32(4): $380-95$. [http://dx.doi.org/10.1016/j.genhosppsych.2010.03.011] [PMID: 20633742]

[16] Butler M, Kane RL, McAlpine D, et al. Does integrated care improve treatment for depression? A systematic review. J Ambul Care Manage 2011; 34(2): 113-25.

[http://dx.doi.org/10.1097/JAC.0b013e31820ef605] [PMID: 21415610]

[17] Behavioral health in primary care [cited 30 March 2015]; Available from: http://www.integration.samhsa.gov/integrated-caremodels/behavioral-health-in-primary-care

[18] Woltmann E, Grogan-Kaylor A, Perron B, Georges H, Kilbourne AM, Bauer MS. Comparative effectiveness of collaborative chronic care models for mental health conditions across primary, specialty, and behavioral health care settings: systematic review and meta-analysis. Am $\mathrm{J}$ Psychiatry 2012; 169(8): 790-804. [http://dx.doi.org/10.1176/appi.ajp.2012.11111616] [PMID: 22772364]

[19] Robinson PJ, Strosahl KD. Behavioral health consultation and primary care: lessons learned. J Clin Psychol Med Settings 2009 ; 16 (1): 58-71. [http://dx.doi.org/10.1007/s10880-009-9145-z] [PMID: 19184376]

[20] Alexopoulos GS, Reynolds CF III, Bruce ML, et al. Reducing suicidal ideation and depression in older primary care patients: 24-month outcomes of the PROSPECT study. Am J Psychiatry 2009; 166(8): 882-90. [http://dx.doi.org/10.1176/appi.ajp.2009.08121779] [PMID: 19528195]

[21] Echeverry D, Duran P, Bonds C, Lee M, Davidson MB. Effect of pharmacological treatment of depression on A1C and quality of life in lowincome Hispanics and African Americans with diabetes: a randomized, double-blind, placebo-controlled trial. Diabetes Care 2009; 32(12): 2156-60.

[http://dx.doi.org/10.2337/dc09-0785] [PMID: 19729522]

[22] Hay JW, Katon WJ, Ell K, Lee PJ, Guterman JJ. Cost-effectiveness analysis of collaborative care management of major depression among low-income, predominantly Hispanics with diabetes. Value Health 2012; 15(2): 249-54.

[http://dx.doi.org/10.1016/j.jval.2011.09.008] [PMID: 22433755]

[23] Szymanski BR, Bohnert KM, Zivin K, McCarthy JF. Integrated care: treatment initiation following positive depression screens. J Gen Intern Med 2013; 28(3): 346-52. [http://dx.doi.org/10.1007/s11606-012-2218-y] [PMID: 23150068]

[24] Druss BG, von Esenwein SA, Compton MT, Rask KJ, Zhao L, Parker RM. A randomized trial of medical care management for community mental health settings: the Primary Care Access, Referral, and Evaluation (PCARE) study. Am J Psychiatry 2010; 167(2): 151-9. [http://dx.doi.org/10.1176/appi.ajp.2009.09050691] [PMID: 20008945]

[25] McGuire J, Gelberg L, Blue-Howells J, Rosenheck RA. Access to primary care for homeless veterans with serious mental illness or substance abuse: a follow-up evaluation of co-located primary care and homeless social services. Adm Policy Ment Health 2009; 36(4): 255-64. [http://dx.doi.org/10.1007/s10488-009-0210-6] [PMID: 19280333] 
[26] Hoge MA, Morris JA, Laraia M, Pomerantz A, Farley T. Core competencies for integrated behavioral health and primary care. Washington, DC: SAMHSA - HRSA Center for Integrated Health Solutions 2014.

[27] American Psychiatric Nurses Association (APNA). APNA primary care statement [cited 1 November 2014]; 2013. Available from: https://www.apna.org/files/public/APNA_Primary_Care_Statement.pdf

[28] Psychiatric-mental health nursing Scope and standards of practice. $2^{\text {nd }}$ ed. Silver Spring, MD: ANA 2013.

[29] All Discussion Board [cited 28 November 2014]; 2014. Available from http://community. apna.org/communities/alldiscussion

[30] International Society for Psychiatric Nurses (ISPN). White paper on integrated care 2005.

[31] Beacham AO, Herbst A, Streitwieser T, Scheu E, Sieber WJ. Primary care medical provider attitudes regarding mental health and behavioral medicine in integrated and non-integrated primary care practice settings. J Clin Psychol Med Settings 2012; 19(4): 364-75. [http://dx.doi.org/10.1007/s10880-011-9283-y] [PMID: 22481239]

[32] Nover CH. Mental health in primary care: perceptions of augmented care for individuals with serious mental illness. Soc Work Health Care 2013; 52(7): 656-68. [http://dx.doi.org/10.1080/00981389.2013.797537] [PMID: 23947541]

[33] PMHNP on line program overview [cited 1 November 2014]; Available from: http:// nursing.uc.edu/academic_programs/postmaster_s_certificate/psych -mental-health.html

[34] Psychiatric Nurse Practitioner Certificate Program [cited 1 November 2014]; Available from: http://nursing.jhu.edu/academics /programs/post-degree/psychiatric/

[35] PMHNP Program Description [cited 1 November 2014]; Available from: http://nur sing.unc.edu/academics/post-masters-programs /psychiatric-mental-health-nurse-practitioner/

[36] Summergrad P, Kathol RG, Eds. Integrated care in psychiatry: Redefining the role of mental health professionals in the medical setting. New York: Springer Science+Business Media 2014.

[37] Reiss-Brennan B. How Intermountain Healthcare's mental health integration is improving care Beckers Hospital Review E Weekly 2014 Oct 31; [cited 30 March 2015]; Available from: http://www.beckershospitalreview.com/hospital-management-administration/ how-intermountainhealthcare-s-mental-health-integration-is-improving-care.html

[38] Geis A, Delaney KR. Integrated health care: strengthening nursing's voice. Arch Psychiatr Nurs 2010; 24(6): 435-7. [http://dx.doi.org/10.1016/j.apnu.2010.08.002] [PMID: 21111298]

(C) McIntosh; et al. Licensee Bentham Open.

This is an open access article licensed under the terms of the Creative Commons Attribution-Non-Commercial 4.0 International Public License (CC BY-NC 4.0) (https://creativecommons.org/licenses/by-nc/4.0/legalcode), which permits unrestricted, non-commercial use, distribution and reproduction in any medium, provided the work is properly cited. 